\title{
Implementation of RME Approach with a Focus on Social Justice in Teaching and Learning Mathematics in Low Socioeconomic Background School
}

\author{
Nurwati Djam'an \\ Universitas Negeri Makassar \\ Makassar, Indonesia
}

\author{
Suradi Tahmir \\ Universitas Negeri Makassar \\ Makassar, Indonesia
}

\author{
Bill Atweh \\ Curtin University \\ Perth, Australia
}

\begin{abstract}
Focusing on social justice issues through Realistic Mathematics Education (RME) in this study has been developed. This study aims at investigating the application of the RME approach with a focus on social justice issues in teaching and learning mathematics. Action research method with the grounded theory is the methodology of this study. The analysis of data consists of preparing and organising data, exploring the general sense of the data, coding, and representing themes by using NVivo 9 software. This study found that there was an inequality for the school participant regarding the discrepancies in conditions of school facilities, the attitudes of the students, their previous knowledge, and the quality of teaching. However, evidence obtained here indicate that the teacher participant has considerable effort into implementing the approach and students from low socioeconomic background have benefited. In particular, the ways the mathematical task or projects incorporated into the classroom have the potential to encourage students in learning mathematics and could reduce the socioeconomic background related learning gap.
\end{abstract}

Keywords- RME; social justice; learning mathematics; low socio economic background

\section{INTRODUCTION}

In reforming mathematics classroom for achieving equity, we need to apply an approach to mathematics teaching that is substantially different from the more traditional approaches [1]. This concept is about using their environment or by using environmental tools or material such as natural resources. The use of the environment is one of the concepts of the sustainability issues or sustainable development concepts to provide more information of the students to gain more knowledge and improve their attitudes to improve environmentally behaviours of the community [2]. The people should have the access for living healthy and sustainable education, especially for women. This concept is similar with realistic mathematics Educations. Furthermore, the authors suggest that students from low socioeconomic backgrounds must learn to crack the code of the mathematics classroom to participate in it successfully.

Students are expected to perceive the correlation between problems encountered in school and the real world and between different task contexts, there is a call to teach mathematics in context. Considerate of the context of mathematics tasks, Realistic Mathematics Education (RME) is rooted in Freudenthal's interpretation of mathematics as an activity. Learning mathematics means solving mathematically everyday life problems is an essential part [3]. The objective of RME is that the students developed mathematics as real experience. These maybe everyday situations, but they may also be fantasy worlds in which the students can immerse themselves, or it is real. Furthermore, RME equips students with problem-solving skills through a focus on real problems. Students are encouraged to solve problems using their mathematical knowledge, experience, and intuition.

Regarding committing to social justice, developing curriculum addresses to the real life of our students. Encouraging young people to examine issues of race, class, and gender, as they build academic competence, or organising activities that promote cooperative skills and spirit, enables classroom teachers to find ways to promote social justice despite the institutional agenda and bureaucratic practices imposed upon us [4]. In particular, social justice in mathematics moves beyond putting mathematics into a social, real world context; it asks students to make use of the mathematics they are studying to make a social change [5]. In this case, students begin to view mathematics as empowering. School mathematics should support students' responsibilities. Furthermore from this ethical perspective, for mathematics to contribute to the student's liability as a citizen. The learning should attempt to engage the student in meaningful and authentic real world problems and activities that not only develop their mathematical capability but also help develop the student's understanding of the social world and contribute to its transformation whenever possible [6]

The combination between the two interest of RME and social justice issues may provide new insights that allow an improved understanding of mathematics education in the broader social context. Indeed, students may develop their mathematical understanding through working in a context that makes sense to them and also it may develop students' awareness of issues within today's society, especially social justice issues, to bring mathematics alive for them. This study 
aims at investigating the application of the RME approach with a focus on social justice issues in teaching and learning mathematics. Particularly examined the effects of the implementation of the RME approach with a focus on social justice issues in mathematics education on the low socioeconomic background school.

\section{METHODOLOGY}

This research is a qualitative research by using action research and grounded theory. In particular, the use of grounded theory and action research as the research methodology in this study is relevant since the application of the approach is a new line of research in Indonesia, and hence grounded research is appropriate as a means of exploration of the phenomenon. Additionally, the use of action research is relevant to develop teaching methods and student learning by integrating social justice with mathematics education.

\section{A. Research Participants}

The school selected in this study is the private school. This school has inadequate resources and facilities. The students come from the low socioeconomic background.

\section{B. Data Collection}

In this study, the methods of obtaining data, namely, field notes, observation, and informal interview. This study observed the process of teaching and learning in the classroom, while the researchers kept field notes. Observations recorded using a video recorder after getting permission from all the participants involved in this study. Also, a voice recorder activated when the researchers conducted interviews with the teacher. After the lesson ended, the researcher conducted an informal meeting with the teacher in their office that allowed her to get feedback and to reflect on the lesson that has just taken place.

\section{Data Analysis}

The analysis of qualitative data consists of preparing and organising data for analysis, exploring the general sense of the data, and coding and representing themes [7]. These steps are in alignment with the analysis of data collection in this research referred to in grounded theory as 'coding' by using NVivo 9 software. Preparing and organising data for analysis in this study including transcribing audio and video recording as soon as possible after the interview and observation.

\section{RESULT AND DISCUSSION}

Coleman \& USA found that characteristics of schooling, facilities, curriculum and teachers made the most difference for low achieving students and those who came to school least prepared regarding the demands of school attendance [8]. Most of the issues are on the discrepancies in conditions and school facilities, the attitudes of the students, their previous knowledge, and the quality of teaching.

\section{A. Condition and School Facilities}

From the observations carried out in this study, the environment of SMP Pelita suffered from poor hygiene and sanitation and general untidiness which led to poor air quality both inside and outside the classrooms. These conditions have become serious problems as they directly affect students' attention and concentration throughout the learning process. Furthermore, the school could not provide adequate numbers of textbooks, library recourses, and other educational resources in the classroom. With the absence of textbooks, the pupils had to take notes during the lesson. Another concern was the overcrowding of classrooms in the low SES school.

However, the use of the RME approach could result in the growth of students' achievement in learning mathematics. As Iriana, the teacher from SMP Pelita stated in the middle of this study, "I can see some of my students are getting active now." This approach to teaching was quite different from her approach to the study. In a relationship with the improvement of all the educational facilities should improve the quality of the environment This related to one of the sustainable goals which are an improvement of the quality of education and promoting the school system for the sustainable education process.

\section{B. The Attitudes of the Students}

In the workshop at the start of the project, Iriana firmly believed that before enrolling at the school; her students' language skills were limited. They lacked knowledge of the words aligned with social issues as considered in this study. Such comments highlight the doubt about the weakness of her students' language skill.

Under the above conditions, intervention should take place at an early stage otherwise the low SES students will be left behind further from the mathematics school aims. There were several efforts from the teacher regarding strategies for dealing with individual differences within a class, and including children with mathematical difficulties. The findings showed that at the beginning of this study, the students from low socioeconomic background seemed to ask fewer questions and were content to write notes about what the teacher said at the start of the lesson. However, during this study, the teachers provided more opportunities for students to express their mathematical thinking and reasoning. As a consequence, students were comfortable and showed better performances in doing mathematics and in sharing their ideas with others. The context of the students' activity that the teachers created encouraged students to participate in the lesson. This study found that learning mathematics assisted students in developing richer understandings of the mathematics concepts. Also, the study revealed that students held positive attitudes toward mathematics.

\section{Prior Knowledge of the Students}

Based on the data collection, students from low SES schools tend to have less prior knowledge of mathematics concepts. Therefore, students tended to have difficulties in the mathematics learning process at the beginning of the study. For example, when Iriana asked the students about the square 
root concept, most of them did not know the definition as the basic mathematical concept for their next learning material. Here, the implication is that the students should have known what was taught in elementary school. Low SES students begin school at a kindergarten or a primary school of lower quality. In particular, according to Iriana, entrance to this private school only required a student to have successfully passed primary school without any school entry examinations.

About the lack of prerequisite knowledge, it is an important concern because as [9] argues that arithmetic often tends to be taught hierarchically. This means that if students lack the prerequisite knowledge early on, they may have difficulty with later lessons. As a consequence, students, in this case, tend to avoid mathematics.

In implementing the RME approach with a focus on social justice, the teacher participants created some student activity sheets, which are connected to real life situation. Also, students were asked to present their solutions or their work in front of the class to help them to understand the mathematics better. Some students from SMP Pelita expressed their sense of enjoyment at some project as mentioned previously because the data were about them so that they engaged with the project individually. Therefore, this approach helps students gain background knowledge because the teachers supplied the missing information.

\section{The Quality of Teaching}

At the beginning of this study, the teachers work throughout the curriculum with their students. The teacher recognised that she must complete their lessons mandated by the syllabus. Furthermore, before this study, the teachers tended to conduct direct instruction and preferred relying heavily on mathematical questions from the textbook. However, the teachers tried to create exercises to enable the students to connect activities to practical contexts. Also, often the teachers become more active in searching for other activities and resources to support teaching.

Furthermore, in the middle of this study, the teachers spoke to the researchers to practice the best approach in every lesson. It indicates the positive endeavour from the teachers for better teaching practices. As a consequence, students demonstrated growth in their engagement. Such comments highlight the importance of considering the use of the RME approach. This indicated that the RME approach is effective means of teaching for students from a low socioeconomic background. Also, the use of practical contexts in this study made mathematics more meaningful and accessible to all students.

\section{CONCLUSIONS}

During this study, findings show that students were involved in the activity of understanding the mathematics concept and the social world in mathematics learning. In particular, during this study, students had a chance to develop mathematics while they learnt social issues through realistic or real context problems. The ways the mathematical task or projects are incorporated into the classroom have the potential to encourage students in learning mathematics. Also, the approach helps students gain background knowledge because the teachers supplied the missing information. As a consequence, some students from the low socioeconomic background school became more active. Moreover, during this study, the teacher participant has considerable effort into implementing the RME approach with a focus on social justice into mathematics lessons. She has tried to create exercises, and student activities connect to practical contexts and social issues. Also, often they have become more active in searching for other activities and resources to support their teaching. Indeed, the RME approach with a focus on social justice was seen to reduce the socioeconomic background related learning gap.

\section{REFERENCES}

[1] R. Z. Jorgensen and R. Niesche, "Equity, Mathematics and Classroom Practice: Developing Rich Mathematical Experiences for Disadvantaged Students.," Aust. Prim. Math. Classr., vol. 13, no. 4, pp. 21-27, 2008.

[2] Abdullah, G. D. Dirawan, and D. N. Pertiwi, "Analysis of sustainable development urban farming (a case study in Makassar South Sulawesi)," Man India, vol. 95, no. 3, pp. 673-684, 2015.

[3] K. P. E. Gravemeijer, Developing Realistic Mathematics Education: Ontwikkelen Van Realistisch Reken/wiskundeonderwijs. CD-[beta] Press, 1994

[4] S. Karp, "Equity claims for NCLB don't pass the test," Rethink. Sch., vol. 17, no. 3, pp. 3-4, 2003.

[5] B. Sriraman, International perspectives on social justice in mathematics education, vol. 1. IAP, 2008.

[6] B. Atweh and K. Brady, "Socially response-able mathematics education: Implications of an ethical approach," Eurasia J. Math. Sci. Technol. Educ., vol. 5, no. 3, pp. 267-276, 2009.

[7] J. W. Creswell, Qualitative inquiry and research design: Choosing among five approaches. Sage publications, 2012.

[8] J. S. Coleman and D. of H. USA, Equality of educational opportunity, vol. 2. JSTOR, 1966.

[9] A. Dowker, Individual differences in arithmetic: Implications for psychology, neuroscience and education. Psychology Press, 2005. 